\title{
EDITORIAL
}

\section{The Editors' dilemma}

I am writing this immediately following the annual meeting of the Editorial Board. At these meetings most of the agenda items select themselves; for example, we say our 'thank-yous' to the editors leaving the Board, welcome new members and discuss possible candidates to replace the areas of expertise of the departing members.

We spend most of the time discussing the way we process papers in the continuous search to improve the reviewing processes, to make them quicker and maintain objectivity and scientific standards. This year we focused especially on the time between receipt and a decision on a paper, which we think from our own experience as authors is one of the more critical times to reduce.

As you may know, the member of the Editorial Board to whom a paper is assigned makes the initial scientific judgement regarding the acceptability or otherwise of a paper, after receiving opinions from referees and a statistical editor where appropriate. My role as Chairman is to confirm the decision, check the editorial report and compose a suitable letter to send to the author. Where I have reservations about the recommendation of the editor after reading the paper and the reports on it, a discussion ensues with the editor to see if we can resolve my concerns.

The final decision to accept or reject a paper lies with the Chairman of the Board, and while in most cases the decision to accept - with or without some revision - or reject is reasonably clear-cut, there are regularly papers where the words 'I am not sure about this paper' appear in the editor's letter.

All editors face this dilemma - whether to reject a paper or ask the author to re-draft or revise the paper - with the thought at the back of one's mind of those seminal papers which some unfortunate editor rejected in the past.

I am always conscious of the fact that all authors who submit papers to the British Journal of Nutrition believe that their papers are acceptable for publication. I doubt whether anyone sends a paper to us to get our views on its inadequacies, as one might when asking a colleague to read a draft of a paper before sending it off to a journal, although I believe that some of the papers we receive have not had the benefit of this, which I would regard as highly desirable, second opinion.

When we decide to reject a paper I think that the author of the rejected paper deserves more than the standard letter with its cursory references to the Editorial Report 'giving the reasons for rejection'. Composing these letters often turns out to be very difficult indeed, because the reason why a paper is being rejected is usually an integration of a large number of points, each of which considered in isolation would be seen as insufficient. This is especially true when the paper is judged as insufficient in content or in its contribution to nutritional understanding, where there is an element of subjectivity in the judgements. Nevertheless, such judgements have to be made and explained to the author. Other papers are received where there are so many comments on the Editorial Report that 'not acceptable in this form' really does not give an adequate impression of what needs to be done in order to produce an acceptable paper. This is of course 'in our view', because we as the Editorial Board and I as Chairman are responsible to the Nutrition Society for the standards of the Journal.

I accept that authors are in the final analysis responsible for what is written in their paper; nevertheless, we could not publish work where we have doubts about the validity 
of the experimental design, the execution of the work, the results obtained or the conclusions drawn from them. We also have to ensure that the paper is written in English that is clear and unambiguous. I also have a responsibility for the financial status of the publications and so have concerns about the length of papers being appropriate, because we can only publish a defined number of pages in any year. In this connection I would ask authors to write concisely and to think very carefully about the length of the papers submitted. I am loath to restrict experimental sections, but very often complex designs can be illustrated far more effectively by flow diagrams than by text. In Results sections one often finds an author who feels obliged to discuss, in the text, every value given in a table, which is unnecessary if the table is properly designed. We often include in our Editorial Reports a request to the author to shorten a discussion. Discussions in particular have a tendency to be verbose, and the text often effectively 'buries' the essential points which the author wants to make. I think that the best strategy is to put the paper to one side for two weeks or so and then return to it with 'fresh eyes', when it is much easier to see where text can be reduced and arguments made more effectively.

However, to return to the dilemma of rejection and of conveying to the author our views in as constructive a way as possible. Sometimes I know or have worked with the author and I am always conscious of my own reactions to such letters, ranging from intense disappointment to a raging view that the editor is a fool not to recognize such a gem of a scientific paper. The letters of rejection sometimes elicit a reply from the author defending the paper at great length. I have one waiting for a reply now.

My response to these letters is, first, to go back to read the paper again. No one is infallible and we may have missed the point or been mistaken in our judgement. Often the letter from the author brings out key findings far more effectively than in the paper, or gives some key methodological details, or supplies additional evidence for the validity of the procedures. Most important of all is the fact that these letters give a new insight into the rationale behind the work and the author's motivating hypotheses. These letters are in fact a salutary reminder of how a scientific paper should be structured. I would like to see some of this passionate defence and commitment to the work evident in the paper itself.

A recent article in the bulletin of the European Association of Scientific Editors suggested that there were three key questions to ask about a submitted paper: Is it new?, Is it True?, and Is it interesting?

I believe that a scientific paper should be interesting to read, not only to the 'cognoscenti' in the field but to the majority of nutritional scientists because the most exciting new research will start at the interfaces between different areas of research, and reading papers from outside our own fields is one very effective way of seeing these opportunities.

D. A. T. Southgate 